\title{
The Hygrothermal Environment and Potential for Mold Growth within a Straw Bale Wall
}

\author{
Kyle Holzhueter*¹ and Koji Itonaga ${ }^{2}$ \\ ${ }^{1}$ Ph.D. Candidate, Graduate School of Bioresource Sciences, Nihon University, Japan \\ ${ }^{2}$ Professor, College of Bioresource Sciences, Nihon University, Japan
}

\begin{abstract}
The present study is the first investigation in Japan to monitor the interstitial hygrothermal environment of a straw bale wall at various depths and heights. Extensive interstitial monitoring has been conducted on a straw bale building in Kyotango City, Kyoto Prefecture known as "Shinrinnobokujo-tango". The purpose of the present study is three-fold: (1) Determine if the interstitial hygrothermal environment of Shinrinnobokujo-tango's south straw bale wall is homogenous, (2) elucidate the interstitial hygrothermal environment of the south wall, and (3) evaluate the potential for mold growth. As a result of the study, the interstitial hygrothermal environment was found to vary by height and depth. In winter, the interstitial area with the lowest temperature and highest relative humidity was the upper, exterior portion of the wall. In summer, the area with the lowest temperature and highest relative humidity was the lower, interior portion of the wall. Mold growth was predicted within the straw bale wall, with the greatest risk being the upper, exterior portion of the wall in winter and lower, interior portion of the wall in summer. These results suggest the need to control moisture in straw bale walls in Japan.
\end{abstract}

Keywords: straw bale building; interstitial hygrothermal environment; moisture; mold

\section{Introduction}

Straw bales are blocks of compressed straw. In straw bale construction, bales are stacked to create bearing or infill walls. According to the Japanese Straw Bale House Association (2009), the first straw bale home in Japan was completed in 2001 in Tochigi Prefecture.

Straw bale construction has numerous advantages: In Japan, straw is a byproduct of rice cultivation and is thus plentiful and locally available. Straw bales are a carbon sink, sequestering carbon during the life of the building (Wihan, 2007). Straw bale walls provide sound insulation, seismic stability, and low fire risk (King, 2006). Straw bale walls are also highly insulative, reducing energy use and $\mathrm{CO}_{2}$ emissions due to heating and cooling (Bigland-Pritchard, 2005). Upon deconstruction, straw bales can safely decompose without becoming landfill.

The greatest concerns of straw bale construction in Japan are moisture and straw's susceptibility to decay. Holzhueter and Itonaga (2008) have investigated the presence of moisture within straw bale walls and the risk of fungal growth.

\footnotetext{
*Contact Author: Kyle Holzhueter, Ph.D. Candidate, Graduate School of Bioresource Sciences, Nihon University, 1866 Kameino Fujisawa Kanagawa 252-8510 Japan Tel: +81-466-84-3364 Fax: +81-466-84-4464

E-mail: kyleholzhueter@yahoo.com

(Received October 8, 2009 ; accepted May 17, 2010)
}

Holzhueter and Itonaga (2008) monitored the interstitial relative humidity and temperature of four straw bale structures in Japan: A home in Yamanashi Prefecture known as "Waraya", a home in Kyoto Prefecture known as "Jinya", an office in Aichi Prefecture known as "Warafuminoie", and an experimental straw bale structure at Nihon University's Center for Natural Environmental Sciences in Kanagawa Prefecture known as "Atom House". The temperature and relative humidity sensors within the straw bale walls of these four buildings are placed within the middle of the bale wall.

However, through extensive monitoring of a straw bale Winery in California, USA, John Straube (2003) of the University of Waterloo, Canada, found that the interstitial hygrothermal environment within straw bale walls is not homogenous and varies according to height and depth perpendicular to the plane of the wall.

Does a single temperature and relative humidity sensor within a straw bale wall reflect the hygrothermal environment of the entire wall? In order to answer this question, extensive interstitial monitoring has been conducted on a milk processing plant run by Amita Corporation in Kyotango City, Kyoto Prefecture known as "Shinrinnobokujo-tango" (Fig.1.).

The purpose of the present study is three-fold: (1) Determine if the interstitial hygrothermal environment of Shinrinnobokujo-tango's south straw bale wall is homogenous, (2) clarify the interstitial hygrothermal environment of the south wall, and (3) evaluate the potential for mold growth. 


\section{Materials and Methods}

\subsection{Structure of Shinrinnobokujo-tango}

Shinrinnobokujo-tango consists of a milk processing plant and storefront where milk and ice cream are sold. Yamatoragumi Corporation designed and built Shinrinnobokujo-tango and consulted with Goichi Oiwa of Slow Design Research Group regarding the design of the straw bale walls and store interior. Takao Kobayashi, a master plasterer, led construction of the straw bale walls and exterior and interior earthen plaster walls. Construction began in 2007 and was completed in 2008. The interior was plastered in December 2007 and was completely dry by March 2008 , taking three months to dry. The exterior was first plastered in December 2007 and plastered a second time in May 2008. The exterior plaster was completely dry by September 2008 .

The straw bale portion of Shinrinnobokujo-tango consists of straw bales surrounding a post and beam structure. The exterior is finished with earthen plaster directly applied to the straw bales. There is a layer of Tyvek separating the straw bales and wooden structure. On the interior side of the post and beam structure, the interior is finished with earthen plaster applied to a lattice of bamboo, creating a $120 \mathrm{~mm}$ gap for wiring etc. between the interior finish and straw bales.

\subsection{Monitoring the Hygrothermal Environment}

In December 2007, indoor, outdoor, and interstitial temperature and relative humidity sensors ${ }^{1)}$ were installed in Shinrinnobokujo-tango, and data recorded at 30-minute intervals by data loggers (Fig.2.). The

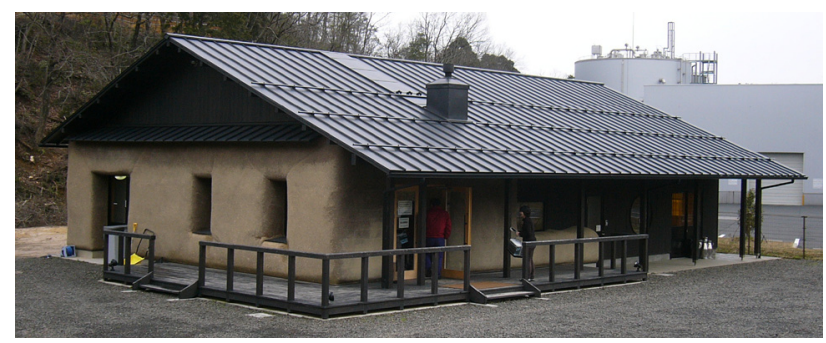

Fig.1. Shinrinnobokujo-tango's Straw Bale Walls

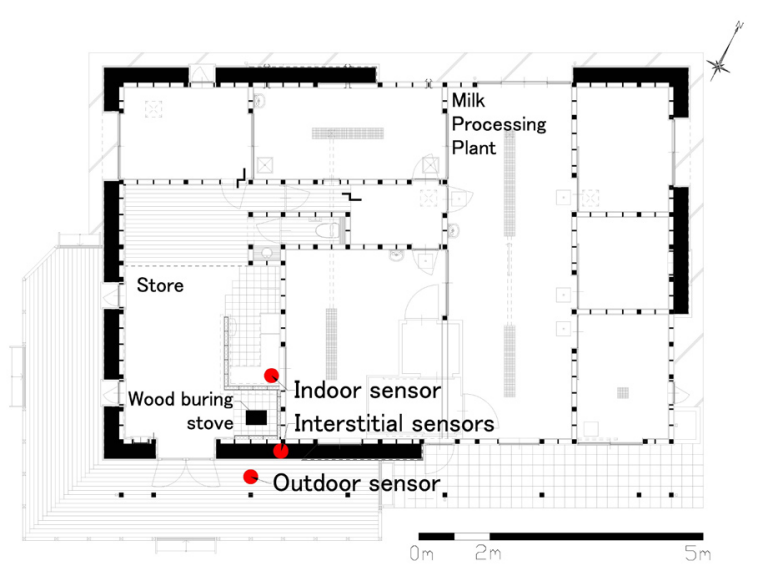

Fig.2. Shinrinnobokujo-tango's Floor Plan with Indoor, Outdoor, and South Wall Interstitial Sensor Locations indoor sensor was located in the store's kitchen area $1500 \mathrm{~mm}$ above floor level, and the outdoor sensor under the south eave, $2500 \mathrm{~mm}$ above ground level.

A "stack" of nine interstitial sensors were installed in the south wall at three heights, low, middle, and high, and three depths perpendicular to the plane of the wall, interior, middle, and exterior (Figs.3. and 4.). Each of the interstitial sensors is labeled with two letters. The first letter designates the height of the sensor: "L" for low, "M" for middle, and " $\mathrm{H}$ " for high. The second letter designates the depth of the sensor, "I" for interior, "N" for interstitial, and "E" for exterior.

During plastering, interstitial relative humidity temporarily rises, but is not indicative of future performance. Therefore, Shinrinnobokujo-tango's interstitial hygrothermal environment will be investigated after the interior and exterior plasters have dried.

Simultaneously depicting the temperature and relative humidity readings of multiple interstitial sensors recorded at 30-minute intervals over an entire year on the same graph results in incomprehensible figures. In order to visually depict the hygrothermal environment over an entire year in an easily understandable manner, monthly averages are graphed.

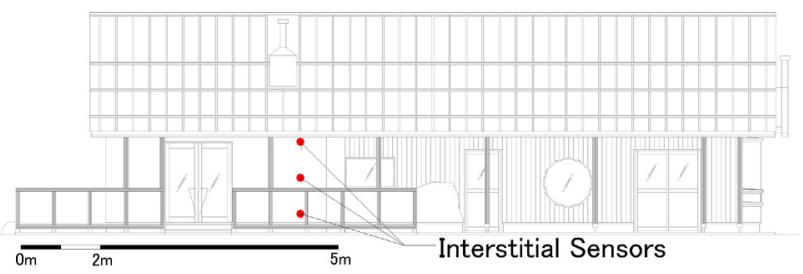

Fig.3. Shinrinnobokujo-tango's South Elevation with Interstitial Sensor Locations

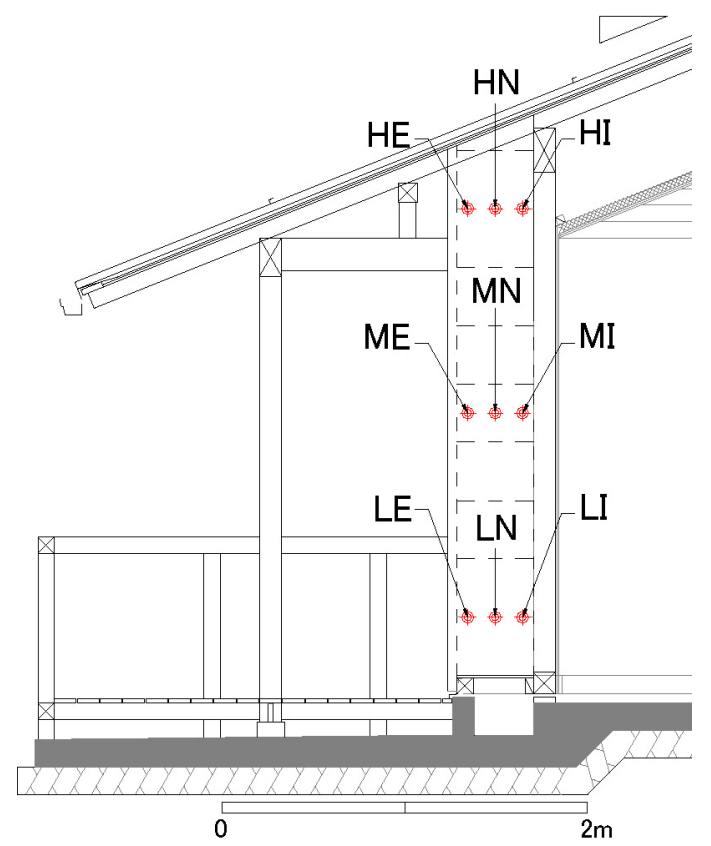

Fig.4. Section of Shinrinnobokujo-tango's South Wall with Interstitial Sensor Locations 
Moreover, temperature and relative humidity are graphed separately.

As stated above, the primary concerns of straw bale construction in Japan are moisture and straw's susceptibility to decay. Given a constant absolute humidity, relative humidity rises as temperature decreases. In terms of interstitial moisture, condensation is most likely to occur on cold surfaces. Therefore, temperature differences between sensors will be identified, which will help explain differences in relative humidity.

The potential for mold growth increases as relative humidity increases (Fog Nielsen, 2002). Thus, areas of high interstitial relative humidity will also be identified.

\subsection{Predicting Mold Growth}

Through a review of the literature, Holzhueter and Itonaga (2008) assumed $80 \%$ to be a safe guideline for
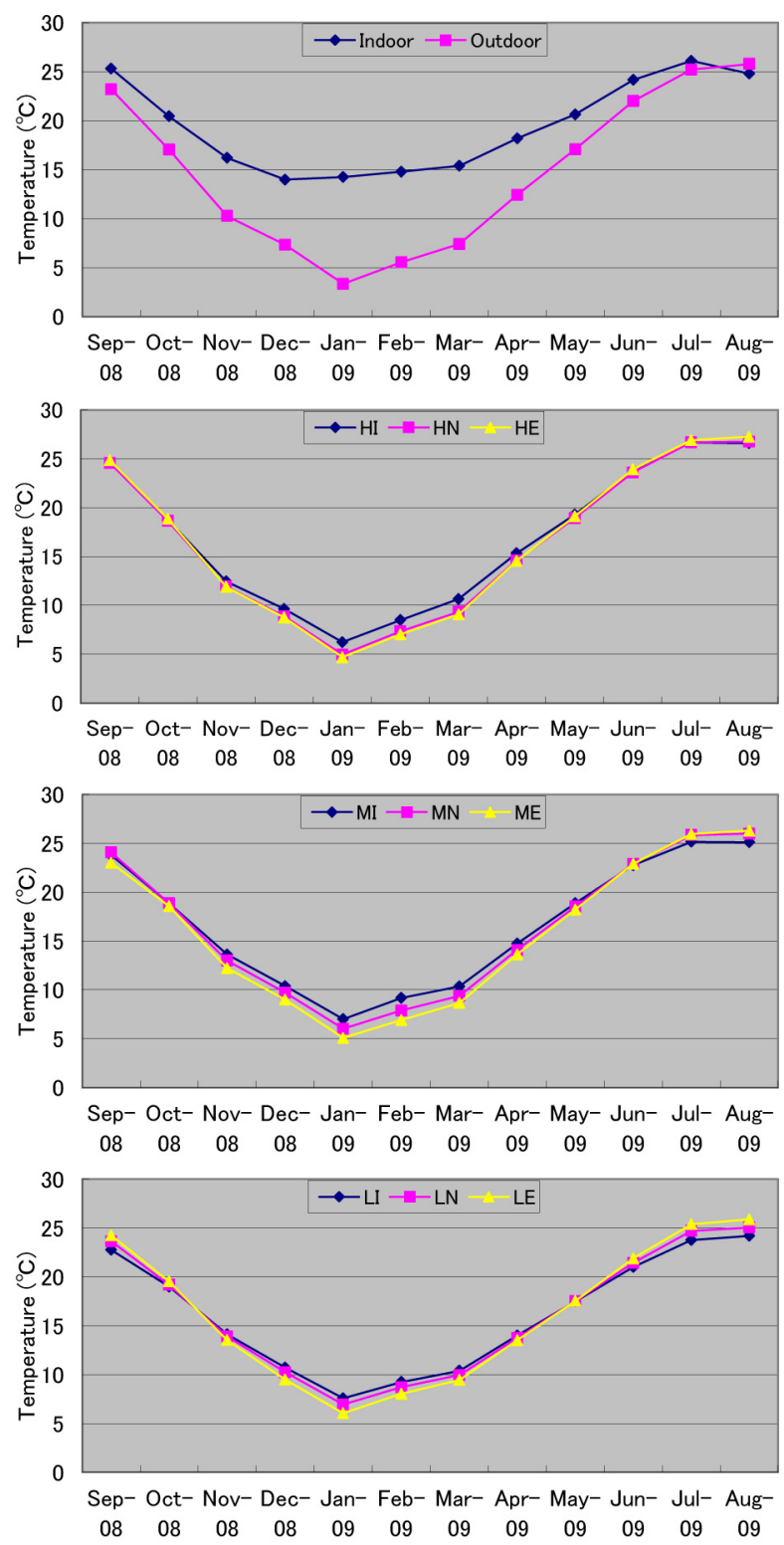

interstitial relative humidity in straw bale walls. Below $80 \%$, it was assumed that that there was little risk of mold growth. Above $80 \%$, mold growth was predicted.

For purposes of this study, $80 \%$ interstitial relative humidity is understood to be a safe guideline for straw bale walls. Below $80 \%$ relative humidity, some biological activity may occur, but is not believed to be detrimental to the life of the building.

\section{Results and Discussion}

Fig.5. depicts the monthly mean temperature and relative humidity of the indoor, outdoor, and south wall interstitial sensors from September 2008 to August 2009.

The outdoor hygrothermal sensor monitors the microclimate surrounding Shinrinnobokujo-tango. The monthly mean outdoor relative humidity meets or exceeds $80 \%$ for half of the year, including the months
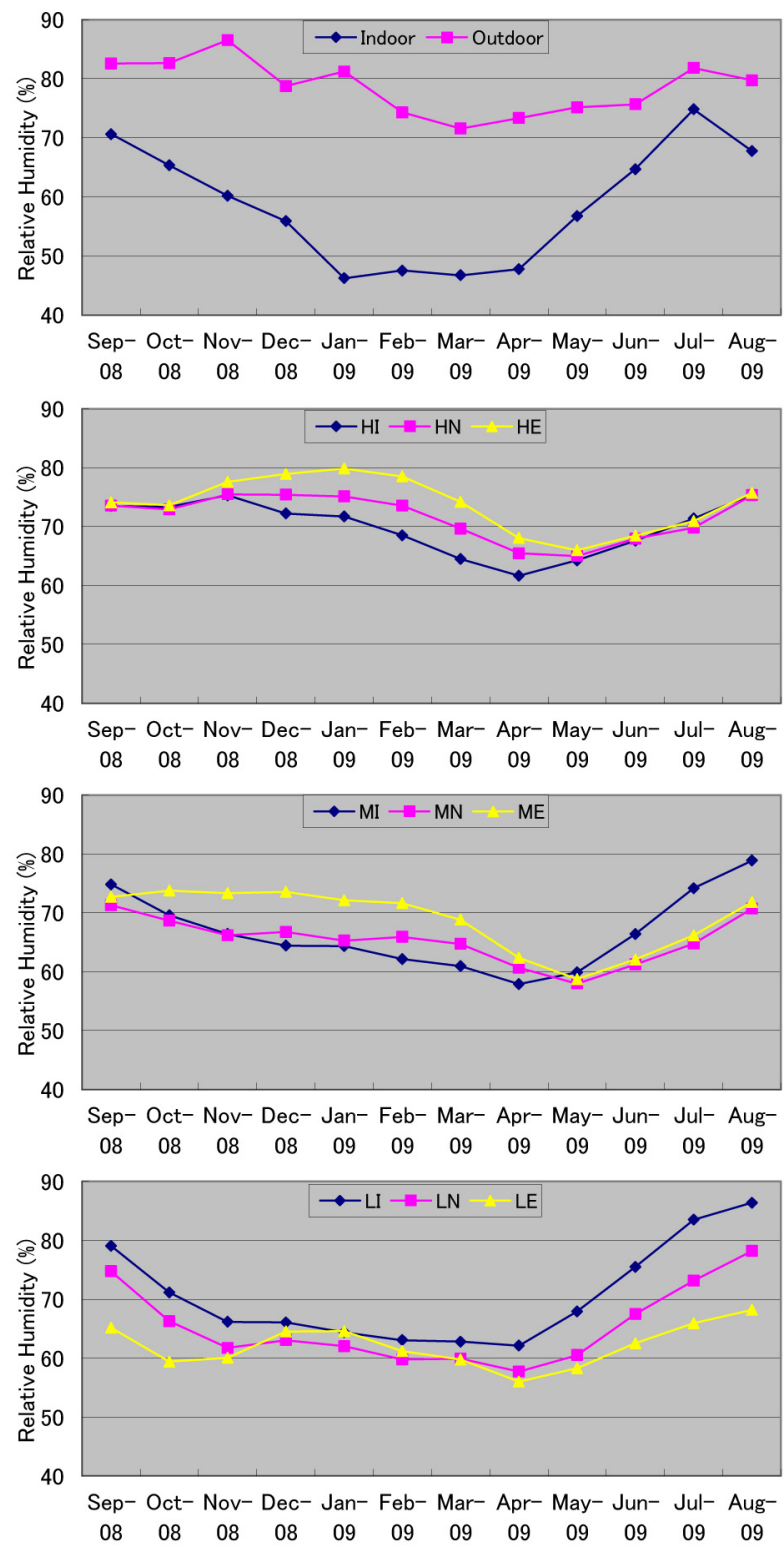

Fig.5. Shinrinnobokujo-tango's Monthly Mean Interstitial, Indoor and Outdoor Temperature and Relative Humidity from September 2008 through August 2009 

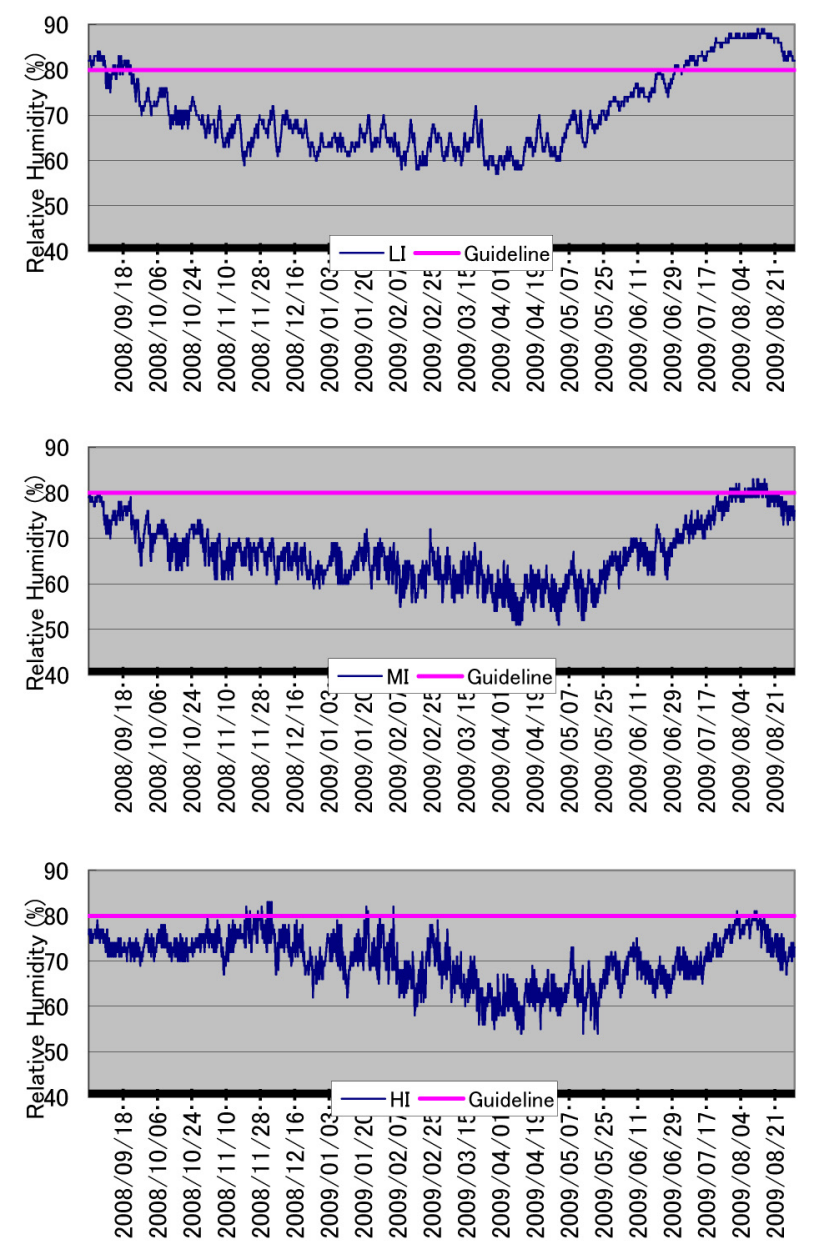
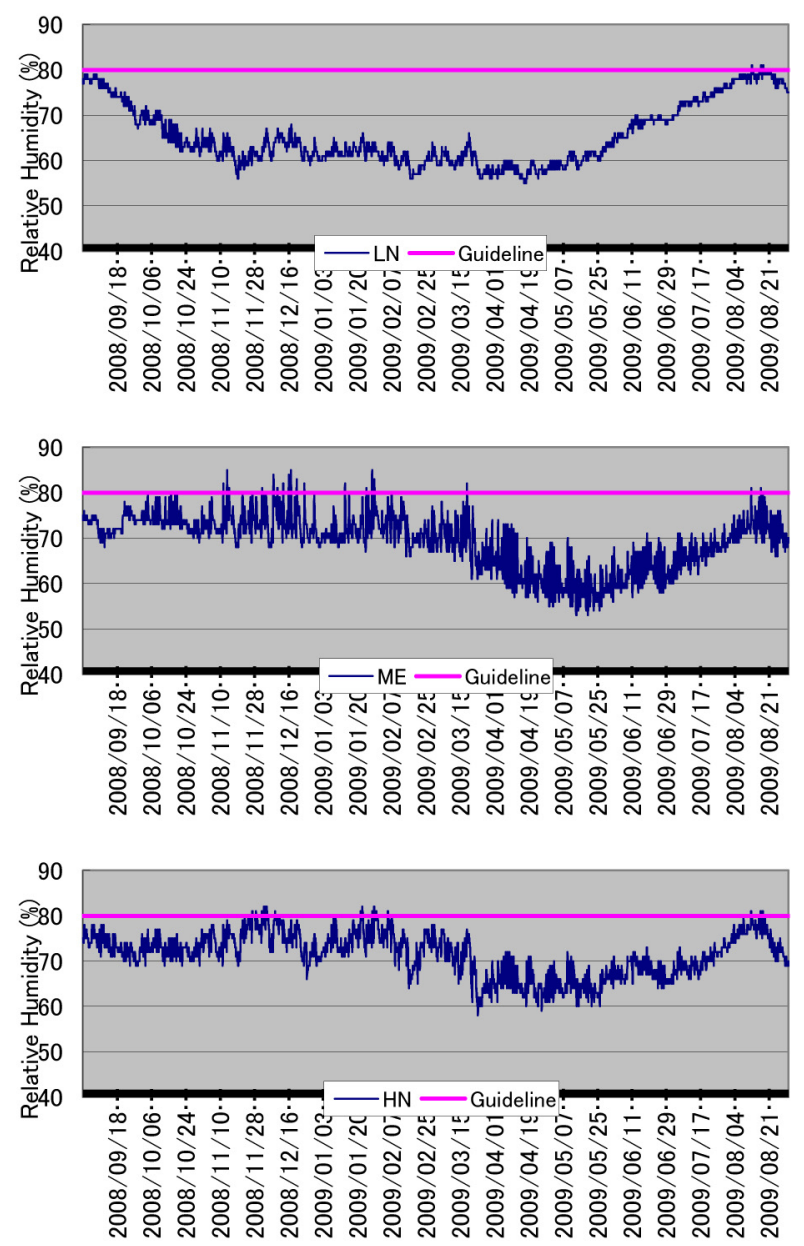

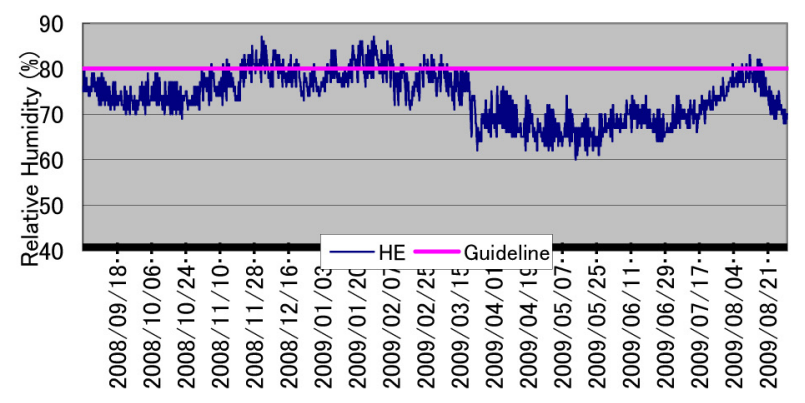

Fig.6. Relative Humidity of Sensors LI, LN, MI, ME, HI, HN, HE from September 1, 2008 through August 31, 2009

September, October, November, January, July, and August. Given that $80 \%$ interstitial relative humidity has been chosen as a safe guideline, this presents a challenge for straw bale construction.

The temperature of interstitial sensors varies by depth and height. In winter, generally the monthly mean temperatures of exterior interstitial sensors are lower than interior interstitial sensors. There is also a temperature gradient according to height. In winter, higher interstitial sensors record lower temperatures than lower interstitial sensors.

In summer, the trend reverses. Generally, monthly mean temperatures of interior interstitial sensors are lower than exterior interstitial sensors. Also, lower interstitial sensors record lower temperatures than higher interstitial sensors.

The relative humidity of interstitial sensors varies by depth and height, inversely to temperature. In winter, the monthly mean relative humidities of exterior interstitial sensors tend to be higher than interior interstitial sensors. There is also a gradient of relative humidity according to height. In winter, higher interstitial sensors record higher relative humidities than lower interstitial sensors.

In summer, the trend reverses. Monthly mean relative humidities of interior interstitial sensors tend to be higher than exterior interstitial sensors. Also, lower interstitial sensors record higher relative humidities than higher interstitial sensors.

Following these trends, in January 2009, HE had 
the lowest monthly mean temperature $\left(4.7^{\circ} \mathrm{C}\right)$ and highest monthly mean relative humidity $(80 \%)$ of the nine interstitial sensors. In August 2009, LI had the lowest monthly mean temperature $\left(24.2^{\circ} \mathrm{C}\right)$ and highest monthly mean relative humidity $(86 \%)$ of the nine interstitial sensors.

Of the nine interstitial sensors, the relative humidity of sensors LI, LN, MI, ME, HI, HN, and HE exceeded the adopted $80 \%$ guideline at some point between September 1, 2008 and August 31, 2009 (Fig.6.). According to the chosen guideline, mold growth is predicted within the south wall.

$\mathrm{HE}$ has the highest relative humidity in winter while LI has the highest relative humidity in summer (Fig.7.). HE exceeded $80 \%$ relative humidity at times between November 2008 and March 2009, and peaked at 87\% relative humidity on December 2, 2008 and January 29, 2009. LI constantly exceeded $80 \%$ relative humidity during the months of July and August, and peaked at $89 \%$ relative humidity on August 12, 13, 15, and 16, 2009.

There is a one to two month time lag between outdoor relative humidity highs and interstitial relative humidity highs. In winter, the monthly mean outdoor relative humidity peaks at $87 \%$ in November and HE's monthly mean relative humidity peaks at $80 \%$ in January. In summer, the monthly mean outdoor relative humidity peaks at $82 \%$ in July and LI's monthly mean relative humidity peaks at $86 \%$ in August. Interstitial relative humidity highs seem to follow outdoor relative humidity highs.

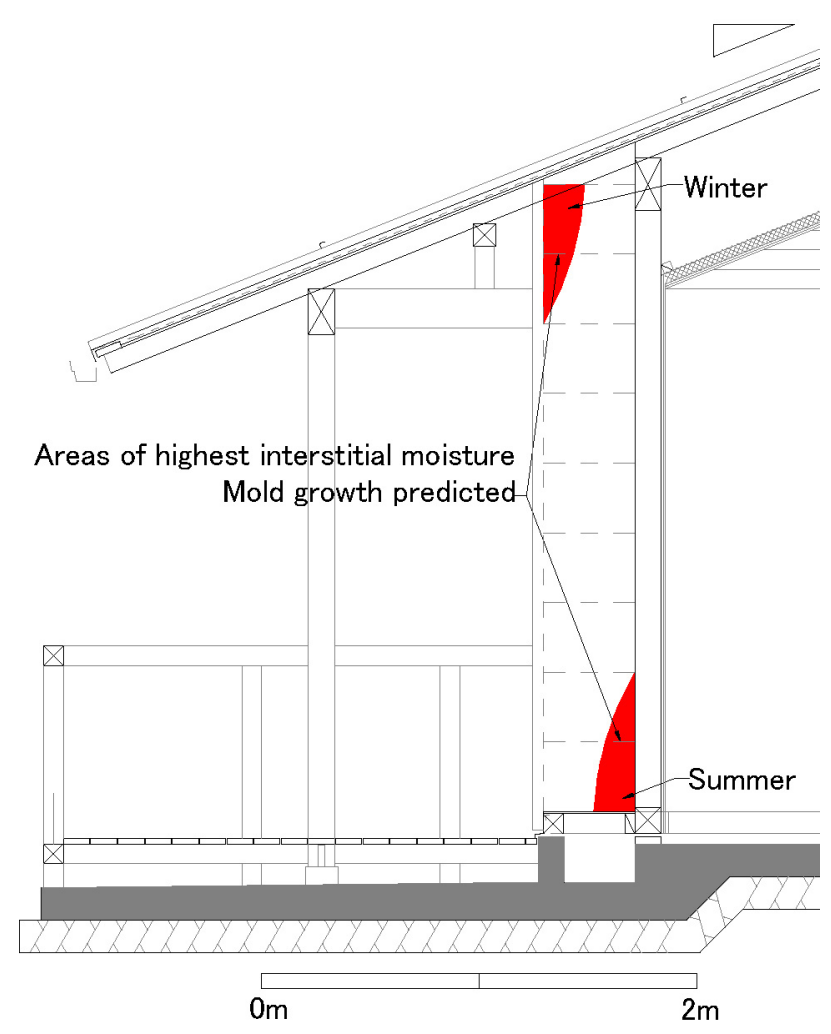

Fig.7. Areas of Highest Interstitial Moisture

\section{Conclusions}

The present study found that the interstitial hygrothermal environment of a straw bale wall varied by height and depth perpendicular to the plane of the wall. In winter, the interstitial area with the lowest temperature and highest relative humidity was the upper exterior portion of the wall. In summer, the area with the lowest temperature and highest relative humidity was the lower interior portion of the wall. The areas in greatest danger of mold growth are the upper exterior portion of the wall in winter and the lower interior portion of the wall in summer. The results of this study emphasize the need to control moisture within straw bale walls in Japan.

\section{Acknowledgments}

The authors would like to thank Amita Corporation and Goichi Oiwa of Slow Design Research Group for accommodating and assisting the research.

\section{Notes}

T and D Corporation's Thermo Recorder sensors and TR-72U data loggers were installed in Shinrinnobokujo-tango. According to the manufacturer, the temperature range of the sensor is $0^{\circ} \mathrm{C}-50^{\circ} \mathrm{C}$, and the relative humidity range is 10 to $95 \%$. The sensors are accurate to $\pm 0.3^{\circ} \mathrm{C}$ between 0 and $50^{\circ} \mathrm{C}$, and $\pm 5 \%$ relative humidity at $25^{\circ} \mathrm{C}$ and $50 \%$ relative humidity.

\section{References}

1) Bigland-Pritchard, M. (2005) An assessment of the viability of strawbale wall construction in buildings in maritime temperate climates. Ph. D. University of Sheffield.

2) Fog Nielsen, K. (2002) Mould growth on building materials: secondary metabolites, mycotoxins and biomarkers. Ph.D. Danmarks Tekniske Universitet, Lyngby, Denmark.

3) Holzhueter, K. and Itonaga, K. (2008) Evaluating the potential for straw decay in straw bale walls in Japan. $7^{\text {th }}$ International Symposium on Architectural Interchanges in Asia. Beijing, China 15-17 October 2008.

4) Japan Straw Bale House Association (2009) First straw bale house in Japan. [Online] Available at: http://www.japanstraw.com/index/ main/03hatuno/03hatuno.html [Last accessed 9 March 2009].

5) King, B. (2006) Design of straw bale buildings: the state of the art. Green Building Press, San Rafael, CA.

6) Straube, J., Schumacher, C. (2003) Monitoring the hygrothermal performance of strawbale walls. [Online] Available at: http://www. ecobuildnetwork.org/pdfs/Winery_Monitoring.pdf

7) Wihan, J. (2007) Humidity in straw bale walls and its effect on the decomposition of straw. MSc. University of East London School of Computing and Technology. 